Research Journal of Applied Sciences 5 (6): 370-375, 2010

ISSN: $1815-932 \mathrm{X}$

(C) Medwell Journals, 2010

\title{
Modelling Chlorophyll Concentrations Using MODIS Satellite Data
}

\author{
Maged Marghany and Mazlan Hashim \\ Institute of Geospatial Science and Technology (INSTEG), \\ University of Teknologi Malaysia, 81310 UTM, Skudai, Johore Bahru, Malaysia
}

\begin{abstract}
Accurate chlorophyll data are critical for determining the magnitude and variability of global ocean primary production, the effect of biological processes on carbon dioxide drawdown in surface waters and for improving the understanding of phytoplankton dynamics in the oceans. In this study, four algorithms have involved to map chlorophyll spatial distribution from MODIS satellite data along east coast of Malaysia: Aiken algorithm, Clark-3-bands algorithm, Gordon algorithm and Normalized Difference Chlorophyll Index (NDCI) algorithm. The results show that the Aiken's algorithm is appropriate for accurately synoptic chlorophyll mapping distribution. In fact, the algorithm performs the lowest root mean square error of $\pm 0.10 \mathrm{mg} \mathrm{m}^{-3}$ as compared to other algorithms. In conclusion, MODIS data can be used as a geomatica tool for accurately mapping of chlorophyll concentration along the coastal water of Malaysia with implementation of Aiken's algorithm.
\end{abstract}

Key words: MODIS satellite data, chlorophyll, Aiken's algorithm, Clark 3-band algorithm, Gordon algorithm, Malaysia

\section{INTRODUCTION}

The major task of biological oceanographers is documentation of temporal and spatial variations in the distribution and abundance of marine organisms over wide scale.

In this context, the major challenge is that most of conventional marine surveying techniques are not able to cover a wide region of ocean in the earth's surface. Quite clearly to understand ocean productivity, biological oceanographers must be able to conduct simultaneous measurements over broad areas of waters (Montres-Hugo et al., 2008; O'Reilly et al., 1998; Pattiaratchi et al., 1994).

This requires the collection of asset of reliable synoptic data that specify variations of critical environmental parameters and of the abundance and distribution of phytoplankton over a wide region for discrete moments (Pattiaratchi et al., 1994). In fact that phytoplankton is marine biological key parameter that described the amount of chlorophyll-a concentration. Further, the highest concentrations of phytoplankton are found on continental shores as compared to offshore. This is could be contributed to the abundance of nutrients that are coming from land. In this context, the concentration of chlorophyll-a (hereafter chlorophyll), the dominant photosynthesis pigment in phytoplankton is widely used as a proxy for phytoplankton abundance and biomass. Fortunately, the application of remote-sensing technology from space is providing biologists with means of acquiring these synoptic data sets.

Consequently, optical remote sensing techniques over $>3$ decades have shown a great promise for mapping chlorophyll-a variation over oceans (Aiken et al., 1995). For instance, Coastal Zone Color Scanner (CZCS) on Nimbus, SeaWiFS and MODIS satellite data provide valuable information about chlorophyll-a concentration. In this context, several algorithms have established to model chlorophyll-a concentration. These algorithms are based on the nonlinear relationship between electromagnetic spectra of the blue and green portions with in situ measurements of chlorophyll-a concentrations. Consequently, scientists used for instance Hyperbolic mathematical algorithm or combination of power with Hyperbolic mathematical algorithm to estimate chlorophyll-a concentration. These algorithms usually use the ratios of reflectance in blue and green bands or combinations of ratios as parameters (Montres-Hugo et al., 2008). In doing so, these algorithms involve a nonlinear statistical regression. Therefore, chlorophyll-a is estimated as function of reflectance ratios in which a nonlinear methods use for developing transfer functions (Pattiaratchi et al., 1994).

In practice, application of the algorithm without preliminary calibration may work accurately but on the other hand it may lead to a large deviation from the real

Corresponding Author: Maged Marghany, Institute of Geospatial Science and Technology (INSTEG), University Teknologi Malaysia, 81310 UTM, Skudai, Johore Bahru, Malaysia 
values of chlorophyll-a. This study, therefore has hypothesized that not all nonlinear algorithms show an excellent promise to estimate a chlorophyll-a concentrations in such tropical area as Malaysia. In this manner, this study aims to determine an appropriate algorithm which can be used accurately to estimate chlorophyll-a concentrations. In doing so, a comparison between Aiken's, Clark, Gordon and NDCI algorithms is carried out using linear regression statistical model to find out accurately algorithm for Malaysian coastal water to determine concentration of chlorophyll-a.

\section{MATERIALS AND METHODS}

Study area: The study area is located along the east coast of peninsular Malaysia between latitude of $1^{\circ} 45-7^{\circ} 45^{\prime} \mathrm{N}$ and Longitude of $100^{\circ} 10^{\prime}-103^{\circ} 10^{\prime} \mathrm{E}$ (Fig. 1). This area is dominated by wind monsoon impacts.

The monsoon winds play a great role to divide the Malaysian climate into South West monsoon season, inter-monsoon season, Northeast monsoon and inter-monsoon between Northeast and Southwest monsoon seasons (Maged et al., 1997, 2009; Maged and Hashim, 2008; Marghany, 2003; Marghany et al., 2002; Marghany, 2001). The maximum wind speed of $10 \mathrm{~m} \mathrm{sec}^{-1}$ can be found during Northeast monsoon period which starts from November-March (Maged et al., 1997). Furthermore, Marghany (2001) stated that east coast of peninsular Malaysia borders the South China Sea, the largest water body in Southeast Asia and faces the continental shelf of Sunda platform which has water depths not exceeding $100 \mathrm{~m}$.

Field data collections: The study is conducted between 2002-2007 along the east coast of peninsular Malaysia. The first phase is carried out in September 2002 along the coastal waters of Kuala Terengganu whereas the second phase is carried out in October 2003 in Phang coastal waters, Malaysia (Fig. 2). Further, the oceanography cruises are conducted on Phang coastal waters during September 2003 and April 2004. In addition, in situ measurements are acquired in Johor coastal waters in October 2004 and January of 2005. Finally, resampling in the coastal waters of Terengganu has carried out in April 2007-June 2007 to ensure accurately in situ measurements. In doing so, 105 sampling locations are chosen to study of Coastal Oceanography of the South China sea (Fig. 1).

Chlorophyll samples were obtained from triplicates of vertical haul at chosen at different transects by using the 122 microns, $0.6 \mathrm{~m}$ of mouth diameter Kilahara net during day time. Samples were fixed with $5 \%$ formaldehyde, buffered with borax. Further, the number of spectral

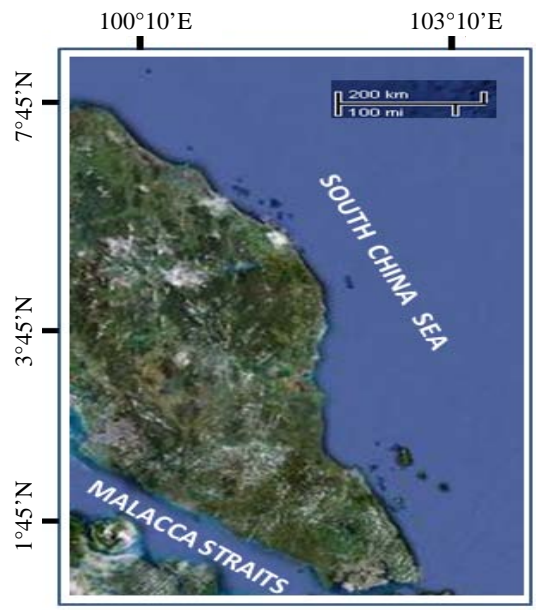

Fig. 1: Study area locations

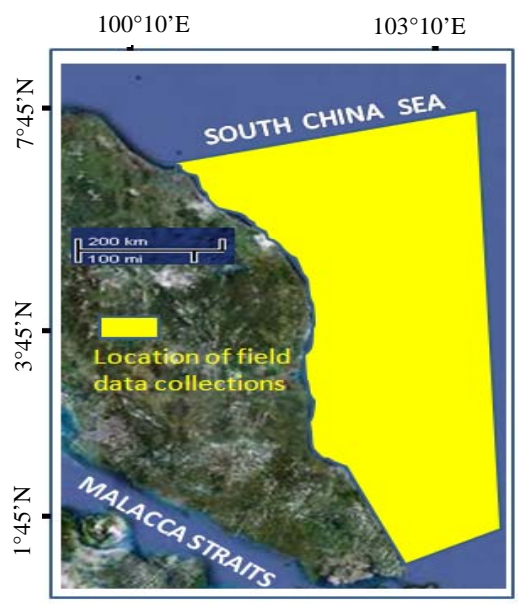

Fig. 2: Location of field data collections

measurements was at least 3 on each occasion and for each of the 35 field visits from September 2002 until April 2007. An average of the reflectance measurement was used to feed into regression equation. The profiling reflectance radiometer (spectroradiometer) has 3 of the MODIS wavelength bands; band 9 (438-338 nm), band $11(526-536 \mathrm{~nm})$, band $12(546-556 \mathrm{~nm})$. Following the procedures done by Montres-Hugo et al. (2008), the underwater sensor was deployed just below the water surface and downwelling irradiance and upwelling radiance were recorded.

According to Montres-Hugo et al. (2008), the reflectance in each spectral channel was calculated as the ratio of the upwelling radiance $L_{u}$ to downwelling irradiance $\mathrm{E}_{\mathrm{d}}$ :

$$
R=\left[\frac{L_{u}}{E_{d}}\right]
$$


Res. J. Applied Sci., 5 (6): 370-375, 2010

Table 1: Empirical algorithms

\begin{tabular}{llll}
\hline Algorithm & Type & Equations & Band ratio $(\mathrm{R})$ and coefficient (a) \\
\hline Aiken's & Hyperbolic & $\mathrm{Chl}=\exp \left[\mathrm{a}+\mathrm{b}^{*} \ln (\mathrm{R})\right]$ & $\mathrm{R}=\left(\mathrm{L}_{\mathrm{W}} 448 / \mathrm{L}_{W} 551\right) ; \mathrm{a}=0.8933$ \\
Clark & Hyperbolic & $\mathrm{Ln}(\mathrm{chl})=\mathrm{a}+\mathrm{b}(\mathrm{R})$ & $\mathrm{R}=1 \mathrm{n}\left[\left(\mathrm{L}_{W} 443+\mathrm{L}_{W} 531\right) /\left(\mathrm{L}_{W} 551\right)\right] ; \mathrm{a}=3.7656$ \\
Gordon & Hyperbolic-power & $\mathrm{Chl}=\mathrm{a}\left(\mathrm{L}_{W} 551 / \mathrm{L}_{W} 443\right)^{b}$ & $\mathrm{a}=1.9333$ \\
NDCI & Hyperbolic & $\mathrm{Ln}(\mathrm{chl})=\mathrm{a}(\mathrm{R})-\mathrm{b}$ & $\mathrm{R}=\left[\left(\mathrm{L}_{W} 443 / \mathrm{L}_{W} 448\right)-\left(\mathrm{L}_{W} 551 / \mathrm{L}_{W} 448\right)\right] ; \mathrm{a}=-3.1773$ \\
\hline
\end{tabular}

With the completion of the optional measurement, a water sample was collected at $1 \mathrm{~m}$ below the water surface by a 51 Niskin bottle transferred to a plastic carboy and put in the dark, prior to further processing in the laboratory which took place approximately $24 \mathrm{~h}$ after the sampling. In the laboratory, chlorophyll-a was determined fluorometrically on duplicated $200 \mathrm{~mL}$ samples, filtered onto $\mathrm{GF} / \mathrm{F}$ filters and extracted for $24 \mathrm{~h}$ in the dark at $4^{\circ} \mathrm{C}$ in $90 \%$.

Algorithms for chlorophyll-a estimation: In practice, chlorophyll-a concentration can be estimated by Gordon algorithm, Clark-3-bands algorithm, Normalized Difference Chlorophyll Index (NDCI) and Aiken's algorithm. The algorithms were used in a single or multiple bands of MODIS data are based on hyperbolic and power function forms. This involves four algorithms which are evaluated in this research (Table 1).

These algorithms are involved Aiken's algorithm and NDCI algorithm (Aiken et al., 1995). Both algorithms are based on the concept of band ratio and they having hyperbolic and power function form. The Aiken's hyperbolic model estimates chlorophyll by a hyperbolic function using two band ratio of band 9 and 10 . The NormalizedDifference Chlorophyll Index (NDCI) algorithm however was implemented three bands as compared to the Aiken's algorithm. The existing coefficients in both algorithms are derived from the regression model of MODIS data and in situ measurements.

As for the satellite imagery, MODIS data where obtained from MODIS website (http://ladsweb.nascom. nasa.gov). MODIS data have pixel of $1 \mathrm{~km}$ at nadir and composite images of several data over the region of interest for a given orbit.

For the years 2002 until 2007 only the Terra and Aqua mode with 250 and $500 \mathrm{~m}$ were available. Geo-located and atmospheric corrected imagery product were collected between the study areas. Therefore, satellite scenes included coastal and oceanic domains. Imagery corresponded to the scenes captured between 1000-1200 local time.

For each pixel and wavelength $(\lambda)$, remote sensing reflectances $\left(\mathrm{R}_{\mathrm{rs}}\right)$ were derived from normalized water leaving radiance (Aiken et al., 1995; Montres-Hugo et al., 2008; O'Reilly et al., 1998; Pattiaratchi et al., 1994):

$$
\mathrm{R}_{\mathrm{rs}}(\lambda)=\left[\frac{\mathrm{nL}_{\mathrm{w}}}{\mathrm{F}_{0}(\lambda)}\right]
$$

Where:

$F_{0}=$ The extraterrestrial solar irradiance

$\mathrm{L}_{\mathrm{w}}=$ Downwelling radiance

Validation of satellite derived chlorophyll-a concentration was carried out with in situ samples of chlorophyll-a fraction. Matching between field measurements of chlorophyll-a and MODIS satellite remote sensing indices of chlorophyll-a concentration was performed using statistical different regression model and Root Mean Square Error (RMSE).

Finally, Root Mean Square of bias (RMS) is used to determine the level of algorithm accuracies by comparing with in situ chlorophyll-a concentration. Further, linear regression model used to investigate the level of linearity of chlorophyll-a concentration estimation from MODIS data. The root mean square of bias equals:

$$
\mathrm{RMS}=\left[\mathrm{N}^{-1} \sum_{\mathrm{i}=1}^{\mathrm{N}}\left(\mathrm{Chl}-\mathrm{a}_{\mathrm{i}}-\mathrm{Chl}-\mathrm{a}_{\text {situ }}\right)^{2}\right]^{0.5}
$$

Where Chl-a is estimated amount from MODIS satellite data and $\mathrm{Chl}-\mathrm{a}_{\text {situ }}$ in situ measurements. The time integrations is performed to determine the possible improvement of RMS.

In doing so, simulations and retrievals were performed within a 2 month period and for each grid point, the retrieved chlorophyll-a concentration was averaged over 6 days during the MODIS satellite passes.

\section{RESULTS AND DISCUSSION}

Regression model is used to discriminate between different Aiken; Clark-3-bands; Clark algorithm and Normalized Difference Chlorophyll Index (NDCI) algorithms to determine appropriate algorithm to estimate chlorophyll-a concentration in Malaysian coastal waters (Fig. 3).

Statistical $\mathrm{R}^{2}$ is varied among Aiken, Gordon, NDCI, Clark 3-band algorithms. Aiken's algorithm has the highest $\mathrm{R}^{2}$ value of 0.95 than other algorithms. Further, 
Res. J. Applied Sci., 5 (6): 370-375, 2010
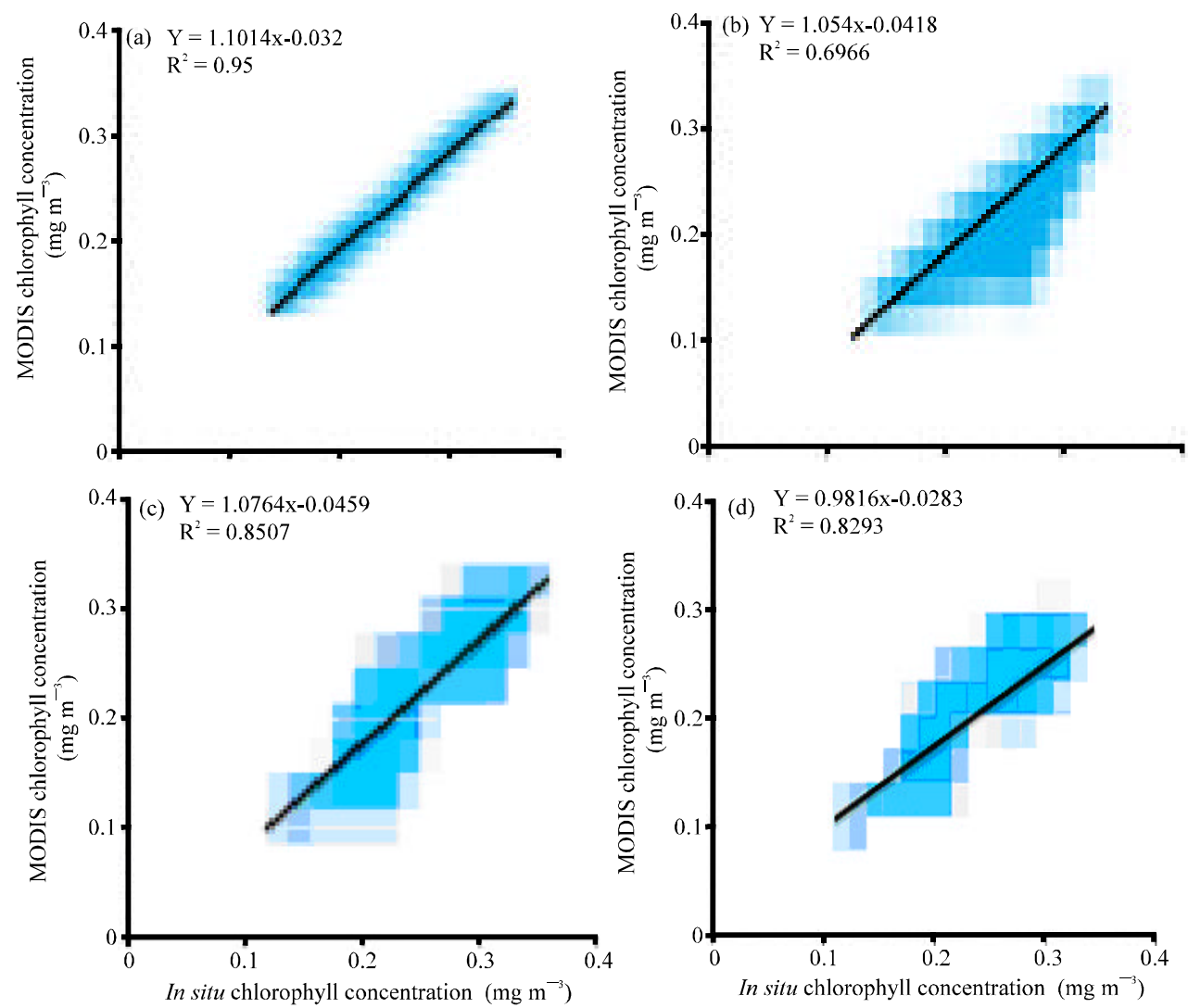

Fig. 3: Regression models of different algorithms; (a)Aiken's algorithm, (b) Clark-3-bands algorithm, (c) Gordon algorithm and (d) NDCI algorithm

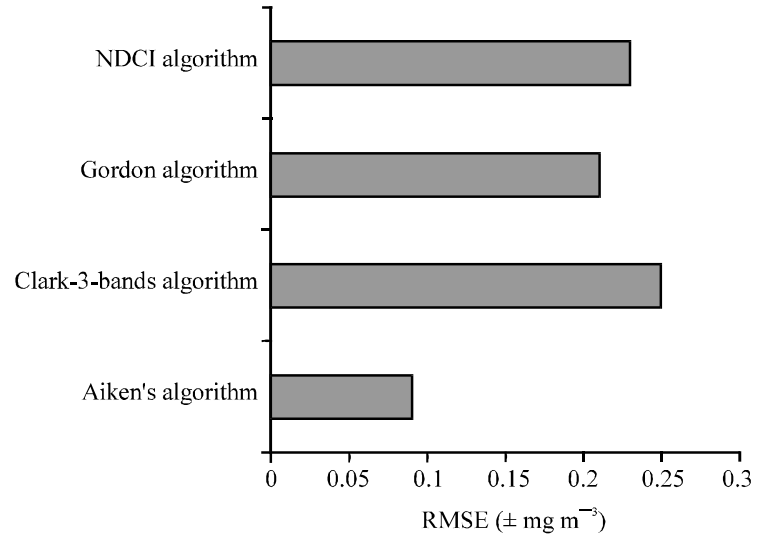

Fig. 4: RMSE graphic bars for different algorithms

the Aiken's algorithm illustrates RMSE of $0.09 \mathrm{mg} \mathrm{m}^{-3}$ (Fig. 4) thus performing a better estimation of Chl-a as compared to other algorithms. In fact, Aiken's algorithm is exponential model whereas express a nonlinear relationship between in situ measurements and satellite MODIS data (Aiken et al., 1995). In this context, the nonlinear relationship has occurred due to impact of near real time of in situ measurements during or before satellite MODIS overpass. In this context, this model which is particularly well suited for characterizing Chl-a concentration rate under limiting circumstances of near real time measurements (Maged and Hashim, 2008; Maged et al., 2009; Marghany, 2003; Marghany et al., 2002).

This study agrees with previous studies of Montres-Hugo et al. (2008), O'Reilly et al. (1998) and Pattiaratchi et al. (1994). Figure 5a-d shows the synoptic maps of chlorophyll concentrations during Northeast monsoon, inter-monsoon and Southwest monsoon periods. In the Northeast monsoon, the chlorophyll concentration pattern seems to have a homogenous variation along the east coast of Peninsular Malaysia.

The maximum chlorophyll-a concentration value of $0.38 \mathrm{mg} \mathrm{m}^{-3}$, however is found in the Northeast monsoon period (Fig. 5a).

In contrast, Inter-monsoon period between Southwest monsoon and Northeast monsoon (September-October) suggests the lowest chlorophyll concentration value of $0.2 \mathrm{mg} \mathrm{m}^{-3}$ as compared to other monsoon periods (Fig. 5d). 
$100^{\circ} 10^{\circ} \mathrm{E}$

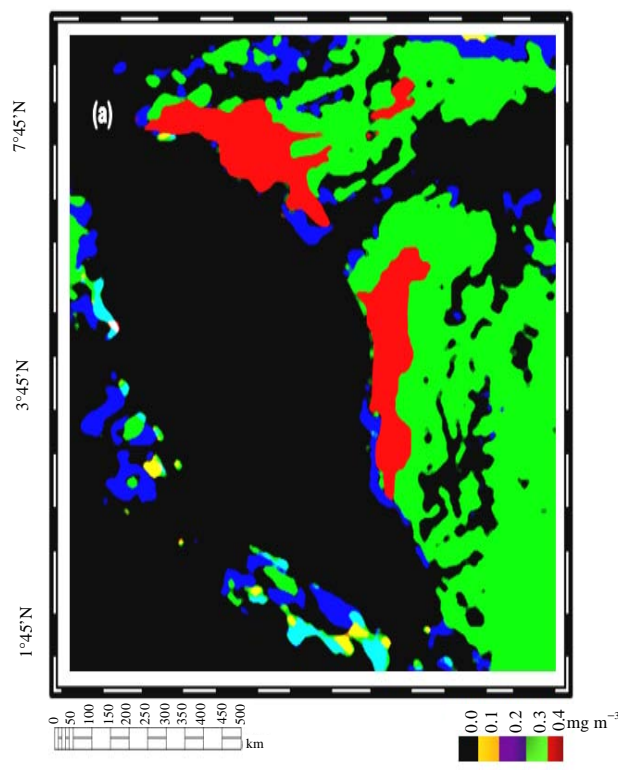

$103^{\circ} 10^{\prime} \mathrm{E}$

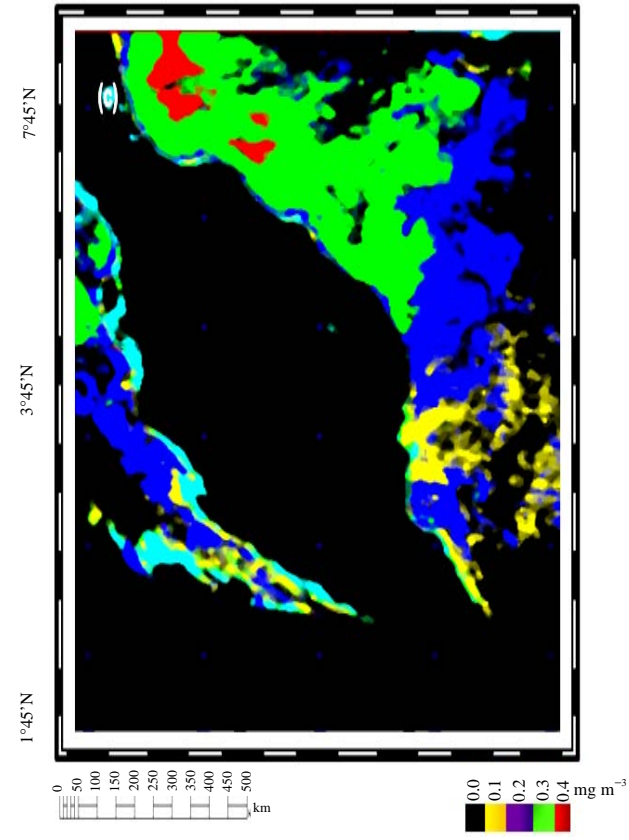

$100^{\circ} 10^{\prime} \mathrm{E}$

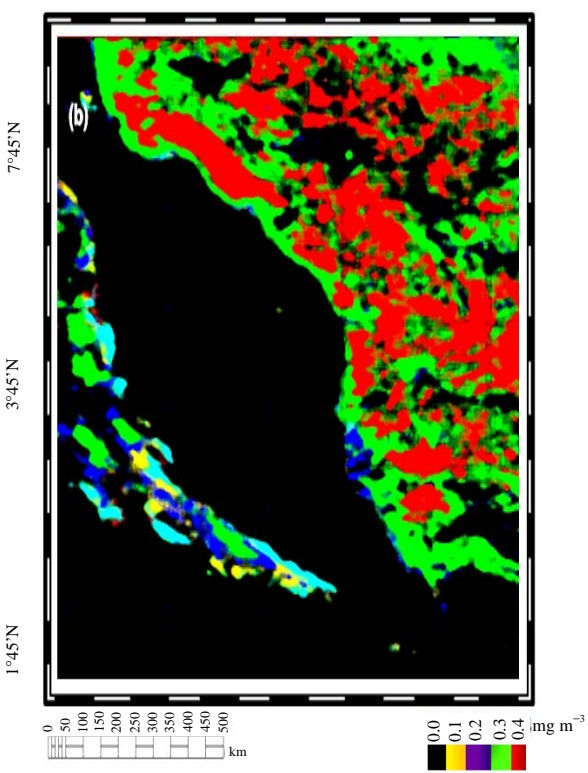

$100^{\circ} 10^{\circ} \mathrm{E}$

$103^{\circ} 10^{\circ} \mathrm{E}$

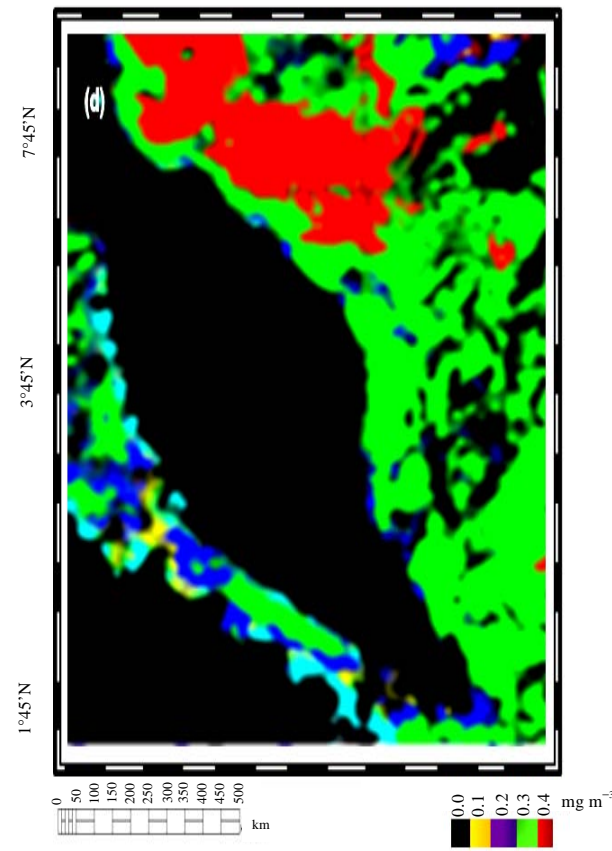

Fig. 5: MODIS chlorophyll-a concentration during (a) Northeast monsoon, (b) Inter-monsoon period (April), (c) Southwest monsoon and (d) inter-monsoon (September-October)

It is interest to find that the chlorophyll concentration decreases gradual as be moved away from the coastline. This might explained the possibilities of upwelling occurrences along the coastline especially during the Northeast monsoon period (Maged and Hashim, 2008).

In general, the spectral characteristics of chlorophyll-a can be mapped by MODIS satellite data. In fact, its spectral signature is located between blue and green wavelength of light spectrum.
Different monsoon periods have different physical ocean parameters such as temperature, salinity and water masses (Montres-Hugo et al., 2008; O'Reilly et al., 1998; Pattiaratchi et al., 1994).

These parameters led to different spatial and seasonal variations of chlorophyll-a concentration along the east coast of peninsular Malaysia. This sort of pattern variation which is function of monsoon wind cycle pattern can be named as vernal bloom. Consequently, it is parallel 
to seasonal cycle of terrestrial plants (O'Reilly et al., 1998). The cycle contains the period of exponential growth and then abrupt decrease resulting from grazing of phytoplankton by zooplankton. Further, the duration of this cycle is a short-period which ranged between 1-2 weeks (Montres-Hugo et al., 2008; O'Reilly et al., 1998; Pattiaratchi et al., 1994).

\section{CONCLUSION}

This study has demonstrated a method to determine appropriate algorithm for chlorophyll-a mapping from MODIS satellite data. The study shows that Aiken algorithm has the lowest RMSE of $\pm 0.10 \mathrm{mg} \mathrm{m}^{-3}$ while Clark-3-bands, Gordon and Normalized Difference Chlorophyll Index (NDCI) algorithms have RMSE values of $\pm 0.25, \pm 0.21$ and $\pm 0.23 \mathrm{mg} \mathrm{m}^{-3}$, respectively.

\section{REFERENCES}

Aiken, J., G.F. Moore, C.C. Trees, S.B. Hooker and D.K. Clark, 1995. The SeaWiFS CZCS-Type Pigment Algorithm. In: SeaWiFS Technical Report Series, NASA Technical Memorandum 104566, Hooker, S.B. and E.R. Firestone (Eds.). Vol. 29, NASA Goddard Space Flight Center, Greenbelt, Maryland, pp: 34.

Maged, M. and M. Hashim, 2008. Estimation of chlorophyll concentration from satellite modis data. Proceedings of the 29th Asian Conference on Remote Sensing, Nov. 10-14, Colombo, Sri Lanka, pp: 1-8.
Maged, M., M. Hashim and A. Cracknell, 2009. 3D reconstruction of coastal bathymetry from AIRSAR/POLSAR data. Chinese J. Oceanol. Limnol., 27: 117-123.

Maged, M.M., N.S. Mohd, L.H. Mohd and I.M. Mohd, 1997. Seasonal thermohaline variation in coastal waters off kuala terengganu, Malaysia. Proceedings of the National Conference on Climate Change, Aug. 12-13, 1996, Universiti Pertanian Malaysia, Serdang, pp: $175-176$.

Marghany, M., 2003. ERS-1 modulation transfer function impact on shoreline change model. Int. J. Applied Earth Observ. Geoinformation, 4: 279-294.

Marghany, M., Z. Ibrahim and J. van Genderen, 2002. Azimuth cut-off for significant wave height investigation along the coastal water of Kuala Terengganu, Malaysia. Int. J. Applied Earth Observ. Geoinformation, 4: 147-160.

Marghany, M.M., 2001. TOPSAR wave spectra model and coastal erosion detection. Int. J. Applied Earth Observ. Geoinformation, 3: 357-365.

Montres-Hugo, M.A., M. Vernet, R. Smith and K. Carders, 2008. Phytoplankton size-structure on the western shelf of the antarctic peninsula: A remote sensing approach. Int. J. Remote Sens., 29: 801-829.

O'Reilly, J.E., S. Maritorena, B.G. Mitchell, D.A. Siegel and K.D. Carder et al., 1998. Ocean color algorithms for SeaWiFS. J. Geophys. Res., 103: 24937-24953.

Pattiaratchi, C., P. Lavery, A. Wyllie and P. Hick, 1994. Estimates of water quality in coastal waters using multi date landsat thematic mapper data. Int. J. Remote Sens., 15: 1571-1584. 